(2) Open Access Full Text Article

\title{
Distinct implications of different BRCA mutations: efficacy of cytotoxic chemotherapy, PARP inhibition and clinical outcome in ovarian cancer
}

This article was published in the following Dove Press journal:

OncoTargets and Therapy

II May 2017

Number of times this article has been viewed

\section{Robert L Hollis \\ Michael Churchman \\ Charlie Gourley}

Nicola Murray Centre for Ovarian Cancer Research, Edinburgh Cancer Research UK Centre, MRC IGMM, Western General Hospital, University of Edinburgh, Edinburgh, UK
Correspondence: Charlie Gourley Nicola Murray Centre for Ovarian Cancer Research, Edinburgh Cancer Research UK Centre, MRC IGMM, Western General Hospital, University of Edinburgh, Crewe Road South, Edinburgh EH4 2XU, UK

Tel +44 I3। $65 \mid 8608$ Fax +44 I3। 7773520 Email charlie.gourley@ed.ac.uk

\begin{abstract}
Approximately a fifth of ovarian carcinoma $(\mathrm{OC})$ is associated with inherited germline mutations, most commonly in the DNA repair genes BRCA1 or BRCA2 (BRCA). BRCA1- and $B R C A 2$-associated $\mathrm{OCs}$ have historically been described as a single subgroup of OC that displays a distinct set of characteristics termed the "BRCAness" phenotype. The hallmarks of this phenotype are superior clinical outcome and hypersensitivity to platinum-based chemotherapy and poly-(ADP-ribose) polymerase (PARP) inhibitors. However, growing evidence suggests that $B R C A 1$ - and BRCA2-associated OCs display distinct characteristics, most notably in long-term patient survival. Furthermore, recent data indicate that the site of BRCA1 mutation is important with regard to platinum and PARP inhibitor sensitivity. Here, we summarize the body of research describing the BRCAness phenotype and highlight the differential implications of different $B R C A$ mutations with regard to clinicopathologic features, therapy sensitivity and clinical outcome in OC.
\end{abstract}

Keywords: ovarian cancer, BRCA1, BRCA2, BRCAness

\section{Introduction}

Ovarian cancer accounts for $\sim 21 \%$ of malignancies diagnosed in the female genital tract and is responsible for $>14,000$ deaths per annum in the US alone. ${ }^{1}$ More than $90 \%$ of cases are epithelial in origin. Ovarian carcinoma (OC) is now recognized to comprise a heterogeneous group of discrete disease entities, each displaying distinct clinical behavior and molecular landscapes. ${ }^{2,3}$ The current standard of care for the first-line treatment of OC comprises maximal surgical resection of the tumor mass and platinum-based chemotherapy, usually in combination with paclitaxel. ${ }^{4}$ While some therapy stratification based on our understanding of disease biology is beginning to emerge in $\mathrm{OC}$ - most notably in the advent of poly-(ADP-ribose) polymerase (PARP) inhibitor therapy - personalization of OC treatment based on histological subtype and molecular characterization remains in its infancy. ${ }^{4,5}$

Hereditary OC accounts for a significant proportion of cases, with around a fifth of patients harboring germline pathogenic sequence variants. ${ }^{6}$ A large proportion of these mutations occur within genes encoding components of the homologous recombination DNA repair (HRR) pathway, most notably in BRCA1 or BRCA2 (BRCA), which together account for $\sim 10 \%$ of OC cases. ${ }^{7}$ Other inherited mutations in HRR pathway-related genes include $B A R D 1, B R I P 1, C H E K 2, P A L B 2$ and $R A D 51 C$, which together account for a minority $(\leq 5 \%)$ of cases. ${ }^{6}$ 
Historically, $B R C A$-associated OC has been described as a single subtype of OC that displays a distinct set of characteristics - frequently referred to as the "BRCAness" phenotype. ${ }^{8}$ However, the differential impact of $B R C A 1$ versus $B R C A 2$ inactivation has become increasingly apparent in recent years. ${ }^{9}$ Here, we summarize the growing body of evidence describing the BRCAness phenotype and highlight the emerging evidence of the distinct implications of different $B R C A$ mutations on the treatment and clinical outcome of OC patients.

\section{Structure and function of BRCA genes BRCAI}

Since its identification in 1994, BRCA1 has become one of the most extensively studied tumor suppressor genes to date. ${ }^{10}$ BRCA1 comprises 24 exons coding for 1863 amino acids, more than half of which are encoded by exon $11 .{ }^{11}$ Its $208 \mathrm{kDa}$ protein product, BRCA1, contains an N-terminal RING domain with E3 ligase activity and a phosphoprotein-binding C-terminal BRCT domain, encoded by exons 2-7 and 16-24, respectively (Figure 1). ${ }^{12-16}$ Exons $11-13$ are known to encode a region with two nuclear localization sequences (NLSs) and protein-binding domains for a multitude of proteins involved in various signaling pathways, including multiple tumor suppressors, oncogenes and DNA repair-associated proteins. ${ }^{17,18}$ These include portions of a coiled-coil domain, which are known to mediate interactions with PALB2, and a serine cluster domain (SCD) whose phosphorylation sites are targeted by ATM and ATR kinases in response to DNA damage. ${ }^{11,19}$ Cancer-predisposing BRCAl mutations are known to occur across these three regions, indicating important tumor suppressive function in each region. ${ }^{11}$

BRCA1 is multifunctional, with roles in the DNA damage response, cell cycle checkpoint maintenance and DNA repair. ${ }^{20-24}$ BRCA1 is known to play a role in maintaining the G1/S, S-phase and G2/M cell cycle checkpoints; however, its principally associated role is in repair of double-stranded DNA breaks (DSB), primarily through HRR. ${ }^{20-24}$ Briefly, BRCA1 associates with ubiquitinated histones at DSBs and facilitates break resection and subsequent recruitment of RAD51 through interaction with PALB2 and BRCA2. ${ }^{25,26}$ Accordingly, loss of BRCA1 expression renders cells hypersensitive to ionizing radiation and interstrand DNA crosslinking agents, consistent with loss of high fidelity DSB repair. ${ }^{20,21}$

\section{$B R C A 2$}

BRCA2 comprises 27 exons encoding 3418 amino acids, which form its $384 \mathrm{kDa}$ protein product, BRCA2, also involved in repair of DSBs through HRR. ${ }^{27,28}$ BRCA2 exon 11 contains eight highly conserved $\mathrm{BRC}$ repeats that are known to interact with RAD51, an essential HRR protein whose family members RAD51C and RAD51D have been identified as OC susceptibility genes (Figure 1). ${ }^{629-33}$ The C-terminal region of BRCA2 also interacts with RAD51 and is known to contain two NLS. ${ }^{34}$

BRCA2 contains a DNA-binding domain comprising an $\alpha$-helical domain, a tower domain and three
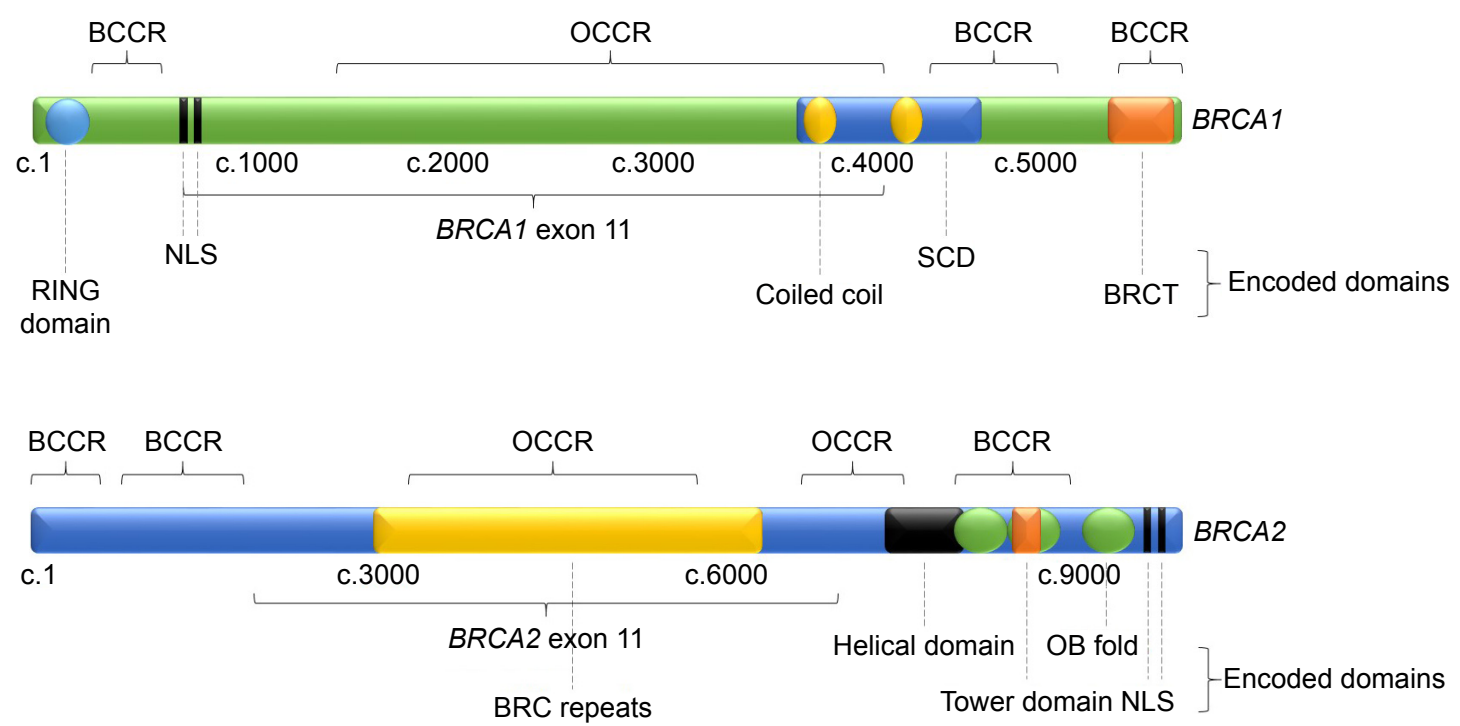

Figure I Structure of BRCAI and BRCA2 genes, showing regions encoding identified protein domains, BCCRs and OCCRs.

Abbreviations: BCCR, breast cancer cluster region; OCCR, ovarian cancer cluster region; NLS, nuclear localization sequence; SCD, serine cluster domain; BRCT, BRCAI C-terminal domain; $O B$, oligonucleotide binding. 
oligonucleotide-binding (OB) motifs for binding single- and double-stranded DNA (ssDNA and dsDNA). ${ }^{26,35}$ Pathogenic mutations have been detected across the length of $B R C A 2$, including in its BRC repeats and DNA-binding domain. ${ }^{9}$

While BRCA1 is multifunctional, BRCA2 appears to function almost exclusively in HRR: it recruits RAD51 to DSB sites, a crucial step in repair. ${ }^{28}$ BRCA2-mutant cells are hypersensitive to DNA damage, accumulate gross DNA damage with passage in culture and fail to recruit RAD51 to DSB sites, but do not appear to demonstrate substantial cell cycle checkpoint impairment. ${ }^{36-39}$

\section{Clinicopathologic features of BRCA- associated OC \\ Cancer predisposition in BRCAI and $B R C A 2$ carriers}

$B R C A$ mutation carriers are predisposed to a number of malignancies, most notably $\mathrm{OC}$ and breast cancer (BC). However, the level of risk for the development of OC and $\mathrm{BC}$ appears dependent upon the affected gene. ${ }^{40,41}$ The average cumulative risk of $B R C A 1$ carriers developing $\mathrm{BC}$ and $\mathrm{OC}$ by the age of 70 is $\sim 50 \%-60 \%$ and $40 \%-50 \%$, respectively, while the equivalent risk in $B R C A 2$ carriers is substantially lower at $\sim 40 \%-50 \%$ and $10 \%-20 \%$, receptively. ${ }^{40-42}$

Growing evidence has begun to elucidate the discrete impact of the type and location of $B R C A 1$ and $B R C A 2$ mutations with regard to cancer predisposition. ${ }^{43-46}$ These studies were founded on the early observation that carriers of mutations in the central portion of $B R C A 1$ exon 11 displayed an augmented risk of OC versus $\mathrm{BC}$ relative to those with mutations in other areas of the gene. ${ }^{43,44}$ Similarly, early observations identified increased risk of OC versus BC in those harboring mutations in exon 11 of $B R C A 2$ versus mutations in other regions. ${ }^{45}$

A recent study sought to more thoroughly investigate the relationship between $B R C A$ mutation position and differential OC versus $\mathrm{BC}$ predisposition in an extensive cohort of $B R C A$ carriers. ${ }^{46}$ Analysis of BRCAl mutation positions revealed three regions associated with increased $\mathrm{BC}$ versus OC risk relative to mutations in other areas of the gene. These conferred a relative hazard ratio $(\mathrm{HR})$ of $\mathrm{BC}$ versus $\mathrm{OC}$ (BC-RHR) ranging from 1.34 to 1.46 . A cluster region within $B R C A 1$ exon 11 conferring increased risk of $\mathrm{OC}$ versus $\mathrm{BC}$ development, relative to other areas of the gene, was also identified $(\mathrm{BC}-\mathrm{RHR}=0.62,95 \% \mathrm{CI}, 0.56-0.70) .{ }^{46}$ This is consistent with previous reports of $B R C A 1$ exon 11 mutations with augmented OC risk. ${ }^{43,44}$ Such BC cluster regions (BCCRs) and OC cluster regions (OCCRs) were also identified in BRCA2: multiple BRCA2 BCCRs and OCCRs were identified with $\mathrm{BC}-\mathrm{RHRs}$ ranging from 1.63 to 2.31 and 0.51 to 0.57 , respectively. ${ }^{46}$

\section{Age at disease onset}

As with many cancer predisposition syndromes, $B R C A$ linked OC is associated with earlier age at diagnosis. ${ }^{47-49}$ Interestingly, BRCA1 carriers appear to develop OC at an average of $\sim 7$ years earlier versus nonhereditary OC patients, while $B R C A 2$ carriers do not display a strong trend for earlier diagnosis (Table 1). ${ }^{47,50-53}$ BRCA1 mutations account for over $80 \%$ of $B R C A$-associated OC diagnosed below the age of 50, while $B R C A 2$ carriers account for $\sim 60 \%$ of $B R C A$ associated OC diagnosed at $>60$ years old, despite the higher prevalence of $B R C A 1$ versus $B R C A 2$ mutations in OC. ${ }^{54}$

\section{Histological subtype of OC}

$\mathrm{OC}$ is largely grouped into five core histologically defined subtypes (histotypes): high-grade serous (HGS), endometrioid, clear cell (CC), low-grade serous (LGS) and mucinous OC, which together represent over $95 \%$ of presenting cases. ${ }^{55}$ HGS OC represents the bulk ( $\left.70 \%\right)$ of cases, while the endometrioid, CC, LGS and mucinous histotypes are reported to account for $\sim 10 \%, 10 \%,<5 \%$ and $3 \%$ of OC, respectively. ${ }^{2,55,56}$ These histotypes represent inherently different tumors, displaying differential chemosensitivity and survival, and are now acknowledged to have discrete developmental origins. ${ }^{57-62}$ Indeed, a wealth of evidence now illustrates that these represent separate disease entities at both the genomic and transcriptomic levels. , $^{3,62-65}$

While a minority of $B R C A$-mutant $\mathrm{CC}$ and endometrioid OC have also been identified, $B R C A$ mutations are associated predominantly with HGS OC. ${ }^{8,47,66}$ Germline $B R C A$ mutations account for $\sim 15 \%$ of HGS OC, with an additional 5\%-10\% displaying somatic $B R C A$ mutations. ${ }^{3,63,67}$

\section{Metastasis to the viscera}

Although the vast majority of OC are diagnosed at advanced stage, disease is frequently confined to the peritoneal cavity, even at recurrence. ${ }^{68}$ Even when distant metastases are present, the majority involve nonvisceral sites.

$B R C A$-linked OC has been associated with an increased frequency of visceral metastasis, most notably to the liver: approximately three in four patients with germline $B R C A$ mutations who develop OC display visceral metastasis, while the rate in nonhereditary OC patients is estimated at less than $20 \%$. ${ }^{69}$ BRCA1 mutation carriers appear to have a 
Table I Characteristics of BRCA I-associated, BRCA2-associated, and BRCA wild-type OC

\begin{tabular}{|c|c|c|c|c|}
\hline & BRCAI-associated OC & BRCA2-associated OC & $B R C A$ wild-type $O C$ & References \\
\hline \multicolumn{5}{|c|}{ Clinicopathological features } \\
\hline \multirow[t]{2}{*}{ Age at diagnosis } & Younger versus WT & Similar to WT & Older versus & $47-52,54$ \\
\hline & & & $B R C A /$-mutant & \\
\hline Histology & \multicolumn{2}{|c|}{ Predominantly HGS OC } & All OC histotypes & $8,47,66$ \\
\hline Visceral metastasis & Highly likely & Likely & Unlikely & 69,70 \\
\hline \multicolumn{5}{|l|}{ Chemosensitivity } \\
\hline \multirow[t]{3}{*}{ Platinum } & Highly sensitive & Highly sensitive & Sensitive & $8,49,53,71,72$ \\
\hline & Exon II and RING domain & May be more sensitive versus & Less sensitive versus & 74,75 \\
\hline & mutants may be more resistant & $B R C A /$-mutant & $B R C A$-mutant & \\
\hline PLD & \multirow{2}{*}{\multicolumn{2}{|c|}{ More sensitive versus WT }} & Less sensitive versus & 96,97 \\
\hline & & & BRCA-mutant & \\
\hline Taxanes & $\begin{array}{l}\text { May be more resistant } \\
\text { versus WT }\end{array}$ & Undetermined & $\begin{array}{l}\text { May be more sensitive } \\
\text { versus } B R C A I \text {-mutant }\end{array}$ & $82,84-87,92,93$ \\
\hline PARP inhibitors & Sensitive & Sensitive & Resistant versus & $72,74,75$ \\
\hline & Exon II and RING domain & & $B R C A$-mutant & $121-130$ \\
\hline \multicolumn{5}{|l|}{ Clinical outcome } \\
\hline \multirow[t]{2}{*}{ PFS } & Superior & Superior & Inferior versus & $53,71,144-149$ \\
\hline & May be inferior to BRCA2-mutant & May be superior to $B R C A I$-mutant & BRCA-mutant & \\
\hline \multirow[t]{2}{*}{ Short-term OS } & Superior versus WT & Superior versus WT & Inferior versus & $53,66,143,147$ \\
\hline & Inferior versus $B R C A 2$-mutant & Superior versus $B R C A I$-mutant & $B R C A$-mutant & $149,155,156$ \\
\hline \multirow[t]{2}{*}{ Long-term OS } & \multirow{2}{*}{ Inferior versus $B R C A 2$-mutant } & Superior versus WT & Inferior versus & $8,47,66,143$ \\
\hline & & Superior versus $B R C A I$-mutant & BRCA2-mutant & $147,149,155,156$ \\
\hline
\end{tabular}

Abbreviations: BRCA, BRCAI or BRCA2; OC, ovarian carcinoma; WT, wild-type; HGS, high grade serous; PLD, pegylated liposomal doxorubicin; PFS, progression-free survival; OS, overall survival; PARP, poly-(ADP-ribose) polymerase.

particular propensity to develop visceral metastases: while investigations to date have been limited, current data suggest that almost all BRCA1 carriers develop disease at visceral sites, compared to only around half of $B R C A 2$ carriers. ${ }^{69,70}$ Furthermore, $B R A C 1$-associated $O C$ has also been shown to display an increased rate of brain metastasis specifically. ${ }^{70}$

\section{Chemosensitivity}

\section{Platinum-based chemotherapy}

A predominant characteristic of the BRCAness phenotype is their sensitivity to platinum-based DNA-damaging agents, even upon repeated exposure at disease recurrence. ${ }^{8,49,71}$ Tan et $\mathrm{al}^{8}$ demonstrated that the majority of $B R C A$-associated OC patients experience partial or complete response to platinum-based agents in the second- and third-line settings, compared to less than half and less than one-tenth of matched controls, respectively. However, they did not compare rates in a BRCA1- and BRCA2-mutant gene-specific manner. The superior sensitivity of $B R C A$-associated $\mathrm{OC}$ to platinum agents was confirmed in later studies of $B R C A$-associated versus nonhereditary OC..$^{49,71}$

Yang et al ${ }^{53}$ compared the frequency of primary platinum sensitivity of $B R C A 1$ versus $B R C A 2$-associated HGS OC. They observed a significantly superior primary platinum sensitivity in the $B R C A 2$ - versus $B R C A 1$-mutant population: $100 \%$ of $B R C A 2$-associated OC ( 25 of 25 in their cohort) displayed primary platinum sensitivity versus $80 \%$ ( 24 of 30 in their cohort) of BRCA1-associated OC. ${ }^{53}$ They also observed a 5.5-month superior platinum-free interval in $B R C A 2$ versus $B R C A 1$ carriers and a "mutator phenotype" indicative of high genome instability in BRCA2-associated OC. ${ }^{53}$ Similarly, Vencken et $\mathrm{al}^{71}$ reported prolonged treatment-free intervals in BRCA2-versus BRCA1-associated OCs, although no significantly superior primary response rate was detected.

While investigations are beginning to dissect the differential implications of $B R C A 1$ versus $B R C A 2$ mutations with regard to chemosensitivity, less is known about the implications of the exact mutation site within each of the two genes. Recent work has begun to elucidate the distinct implication of frameshift-inducing mutations that occur in exon 11 of $B R C A 1 .^{72}$

In vitro, cells harboring $B R C A 1$ exon 11 frameshifting mutations (E11mut) were found to express a BRCA1 isoform missing the majority of exon 11 (BRCA1 $111 \mathrm{q})$. While wildtype cells and cells harboring mutations outside of exon 11 (OE11mut) displayed resistance and sensitivity to cisplatin, respectively, E11mut cells displayed partial platinum resistance. ${ }^{72}$ E11mut cells were able to form RAD51 and 
BRCA1 foci in response to ionizing radiation, indicating at least partial HRR proficiency. Interestingly, a recent investigation of $O C$ patients harboring $B R C A 1$ exon 11 mutations revealed no significantly superior platinum response rate versus the wild-type population. ${ }^{73}$

While the functional characterization of $B R C A 1$ exon 11 remains poor, shrouding the mechanisms that underpin the partial HRR proficiency of E11mut cells, mutations in better characterized portions of the gene have also been correlated with chemosensitivity. ${ }^{74,75}$ Recent investigations suggest that while BRCA1 RING domain function appears important for tumor suppression, hypomorphic BRCA1 isoforms lacking RING domain function display platinum resistance. ${ }^{74,75}$ Introduction of the missense $\operatorname{rrcal}^{\mathrm{C} 61 \mathrm{G}}$ mutation into murine models demonstrated the poor efficacy of platinum agents against rcal $^{\mathrm{C} 61 \mathrm{G}}$ breast carcinomas in a study by Drost et al. ${ }^{74}$ They later compared the effects of two BRCA1 truncating mutations, reflecting two known founder mutations in the Ashkenazi Jewish population, on chemosensitivity. ${ }^{75-77}$ This study demonstrated that introduction of brcal $1^{185 \text { stop, }}$ reflective of the $B R C A 1^{185 \text { delAG }}$ founder mutation, led to production of a RING-less BRCA1, which mediated resistance to cisplatin. ${ }^{75}$

Together, these data demonstrate a clear differential impact for different $B R C A$ mutations. While both $B R C A 1$ and $B R C A 2$ mutations confer superior sensitivity to platinum-based chemotherapy, this phenotype may be exaggerated in BRCA2-associated OC. This is perhaps because $B R C A 2$-associated $\mathrm{OC}$ is rendered HRR defective to a greater extent than $B R C A 1$-associated tumors, manifesting as extensive genomic instability and exquisite sensitivity to DNA damage. ${ }^{53}$ Furthermore, evidence that not all BRCA1 mutations are equal is beginning to emerge. Specifically, mutations in exon 11 and mutations that abrogate RING domain function appear to result in the production of hypomorphic BRCA1 isoforms that mediate resistance to platinum agents but still predispose carriers to OC development. ${ }^{72-74}$ This is consistent with the multifunctional role of BRCA1 in tumor suppression and suggests that multiple aspects of BRCA1 functionality, particularly RING domain function, appear dispensable for HRR function.

\section{Taxanes}

Taxanes are typically used in combination with platinum agents in the treatment of OC but can also be used as single agents, usually in the context of platinum resistance. ${ }^{4,78-80}$ They are distinct from DNA-damaging agents in their mechanism of action, primarily functioning via induction of cell cycle arrest at the spindle assembly checkpoint through disruption of microtubule disassembly. ${ }^{81}$ Paclitaxel sensitivity may therefore be dependent on intact cell cycle checkpoint regulation. Indeed, paclitaxel treatment has been shown to induce acute G2/M arrest in the context of BRCA1 expression. ${ }^{82}$ Given both the known function of BRCA1 in cell cycle checkpoint regulation and the suggestion that there may be an inverse relationship between paclitaxel and cisplatin sensitivity in a range of malignancies, cells may be expected to demonstrate paclitaxel resistance in the absence of BRCA1 function..$^{23,24,83}$

A number of in vitro studies have provided evidence that BRCA1 may play a role in modulating paclitaxel sensitivity. ${ }^{82,84-89}$ BRCA1-defective BC and head and neck squamous cell carcinoma (HNSCC) cells are more resistant to paclitaxel treatment versus BRCA1-proficient cells, suggesting BRCA1-associated OC may display paclitaxel resistance. ${ }^{82,84-87}$ Additionally, BRCA1 loss appears to modulate microtubule dynamics rendering them less susceptible to the action of paclitaxel. ${ }^{88}$ However, some in vitro studies have reported conflicting results on the role of BRCA1 in modulating taxane sensitivity. ${ }^{90}$

In line with the notion that BRCA1 deficiency may mediate taxane resistance, expression of BRCA1 was associated with longer time to progression in a taxane-treated cohort of BC. ${ }^{91}$ However, clinical data regarding the sensitivity of $B R C A$-linked OC to taxane monotherapy are severely limited, with most data described in the context of combination with platinum agents. There has been a suggestion that OC expressing high BRCA1 mRNA levels may benefit from addition of taxanes to platinum, while those with low levels do not, though these data are yet to be confirmed in a comprehensive cohort of OC. ${ }^{92}$ It has been shown that $B R C A$-linked OC can benefit from paclitaxel monotherapy in both the platinum-sensitive and platinum-resistant relapsed disease settings (response rate $60 \%, 9$ of 15 patients and 33\%, 3 of 9 patients, respectively); however, meaningful comparison of taxane monotherapy efficacy between $B R C A$-linked and $B R C A$ wild-type OC has not been conducted. ${ }^{93}$ Critically, the existing data have examined $B R C A$-associated $\mathrm{OC}$ as a single entity.

While the current data suggest that BRCA1-associated OC may be more resistant to paclitaxel, further studies are required to investigate this relationship in the clinical setting. ${ }^{71}$ Given the preclinical evidence suggesting that $B R C A 1$ mutation specifically may mediate taxane resistance, a comprehensive comparison of $B R C A$-mutant versus $B R C A$ wild-type $\mathrm{OC}$ in a gene-specific manner, is now needed to 
elucidate the implication of $B R C A$ status with regard to taxane monotherapy. Because BRCA2 appears to function almost exclusively in HRR, and the mechanism of action of taxanes does not seem to involve induction of DNA damage, there is no clear rationale for differential paclitaxel sensitivity between $B R C A 2$-associated and BRCA wild-type OC. This represents a potential pitfall for therapeutic stratification of taxanes while all $B R C A$-associated OCs continue to be considered as a single clinical entity. Future stratification within this population specifically will require a wider appreciation of the distinction between "BRCA1ness" and "BRCA2ness" in clinical practice.

\section{Nonplatinum DNA-damaging agents}

Nonplatinum nontaxane chemotherapies are also used in the treatment of OC, primarily in the platinum-resistant relapsed disease setting. ${ }^{94,95}$ Pegylated liposomal doxorubicin (PLD) represents one such drug whose mechanism of action involves DNA damage.

Retrospective studies examining differential response rate to PLD have reported superior response and superior clinical outcome after PLD treatment in BRCA-associated OC versus nonhereditary disease. ${ }^{96,97}$ Differential sensitivity to nonplatinum DNA-damaging agents between $B R C A 1$ and $B R C A 2$-mutated $\mathrm{OC}$ may be expected to reflect those observed for platinum agents; however, these comparisons are yet to be made in the context of PLD monotherapy. Similarly, mutations in BRCA1 exon 11 or mutations that affect RING domain function may be expected to confer differential sensitivity phenotypes versus other BRCA1 mutations.

\section{Intraperitoneal chemotherapy administration}

While the majority of OC treatment is given intravenously (IV), chemotherapy may also be administered intraperitoneally (IP). ${ }^{4,98,99}$ IP chemotherapy achieves higher concentrations of drug within the peritoneum compared to IV administration, delivering dose intense chemotherapy to the tumor. ${ }^{99-101}$

Multiple randomized trials have shown a survival benefit for IP administration in advanced-stage OC, particularly in the context of optimal surgical debulking. ${ }^{102-106}$ Although uptake of IP administration has increased, IV therapy remains the predominant treatment protocol in many centers. ${ }^{107}$ Cost and resource implications for IP administration, as well as increased therapy-associated gastrointestinal toxicity, pain, and infection among IP-treated patients, have undoubtedly contributed to variable uptake of treatment regimens. ${ }^{108}$ Thus, identification of OC subgroups who are likely to benefit most from IP administration is an area of keen research interest.

Because $B R C A$-mutant $\mathrm{OC}$ is hypersensitive to platinum agents, it is plausible that $B R C A$ status modulates the efficacy of this dose intense administration route. This hypothesis has in part been explored in the GOG 172 study: this phase III trial comparing IP versus IV cisplatin and paclitaxel reported greater clinical benefit for OC in the IP arm whose patients expressed low levels of BRCA1 protein. ${ }^{109}$

These data suggest an interaction between $B R C A$ status and administration route: the higher concentrations of chemotherapy achieved locally during IP treatment may well be particularly effective in treating HRR-defective tumors. Importantly, these data were limited to immunohistochemistry of BRCA1 protein, and we therefore await translational analysis of IP-treated OC with matched sequencing data for both $B R C A 1$ and $B R C A 2$ in order to fully overlap these genomic features with IP chemotherapy outcome. Analysis of IP chemotherapy efficacy in $B R C A$ wild-type OC will undoubtedly shed light on whether the clinical benefit, if any, experienced in this patient group is outweighed by excessive toxicity.

\section{Neoadjuvant chemotherapy}

Historically, standard OC treatment begins with primary debulking surgery (PDS) of the tumor mass followed by adjuvant platinum-based or platinum-taxane combination chemotherapy. ${ }^{4}$ However, neoadjuvant chemotherapy (NAC) followed by interval debulking surgery (IDS) is increasingly used in OC management and is thought to reduce postsurgical mortality and morbidities. ${ }^{10,111}$ Two large trials have demonstrated NAC as noninferior to PDS in the treatment of advanced stage OC. ${ }^{110,112}$ However, a recent multiinstitutional study reported inferior OS in NAC-treated OC with stage IIIC disease who achieved optimal primary surgical debulking, and there is a clear need to dissect exactly which OC patients will benefit most from NAC versus PDS. ${ }^{113}$

Although there has been no prospective comparison of NAC versus PDS in $B R C A$-associated OC specifically, early data are suggesting that $B R C A$-mutant $\mathrm{OC}$ may be associated with improved response to NAC. ${ }^{114}$ These findings are consistent with the association between $B R C A$ mutation and hypersensitivity with platinum..$^{8,49,71}$

Alarmingly, and in keeping with the concern that NAC may promote platinum resistance, the limited data available suggest that NAC may provide a selection pressure toward $B R C A$-proficient cells. ${ }^{114}$ NAC may therefore compromise the exquisite platinum sensitivity of $B R C A$-associated OC 
by exposing a clonally diverse mass to the selection pressure of DNA-damaging agents. ${ }^{115,116}$ Thus, BRCA carriers may benefit most from PDS followed by adjuvant chemotherapy directed at residual disease, in the hope that HRR-proficient subclones representing a route of chemoresistance may have been surgically removed prior to application of a selection pressure.

\section{Sensitivity to PARP inhibition}

Cells harboring $B R C A 1$ or $B R C A 2$ mutation are heavily reliant upon PARP-mediated DNA repair of ssDNA breaks. ${ }^{117}$ PARP-inhibited cells are thought to accumulate ssDNA damage, which is converted to DSBs during subsequent cellular replication, whether through defective ssDNA damage repair or PARP trapping at DNA damage sites. ${ }^{117-120}$ In the context of HRR deficiency, accumulation of unrepaired DSBs results in cytotoxicity and cell death, and $B R C A$ mutations therefore exhibit synthetic lethality with PARP inhibition. ${ }^{121}$ Indeed, the PARP inhibitors olaparib, rucaparib and niraparib have shown marked antitumor activity in monotherapy or maintenance phase II and phase III trials of OC patients with particularly marked efficacy demonstrated in patients with germline $B R C A$ defects. ${ }^{122-130}$ Olaparib and rucaparib are now licensed by the FDA as a monotherapy for recurrent $\mathrm{OC}$ in this patient population and olaparib is licensed by the European Medicines Agency as a maintenance therapy following a response to chemotherapy in patients with germline or somatic $B R C A$ mutations.

While both $B R C A 1$ and $B R C A 2$ mutations sensitize cells to PARP inhibition, the affected gene appears to have a modulating effect on sensitivity: BRCA1-defective cells demonstrate $\sim 60$-fold increase in sensitivity to olaparib versus $B R C A$ wild-type cells, while the corresponding increase in sensitivity in BRCA2-defective cells is $\sim 130$ fold. ${ }^{121}$ However, data regarding differential response rates of $B R C A 1$ versus $B R C A 2$ carriers to PARP inhibition in the clinical setting are currently limited. Some data suggest a trend for slightly superior response rate in $B R C A 2$-associated OC treated with PARP inhibitors, while others report no difference in sensitivity or PFS, and the consensus remains that $B R C A$-associated OC is considered as a single clinical entity with regard to PARP inhibitor sensitivity. ${ }^{122-130}$

While the distinction in sensitivity between $B R C A 1$ and $B R C A 2$-associated OCs remains unclear in the clinical setting, emerging in vitro data suggest that the location of BRCA1 mutation may influence the efficacy of PARP inhibitors. $^{72,74,75}$ Consistent with the notion that the hypomorphic BRCA1 isoform BRCA1 $\Delta 11 \mathrm{q}$ can mediate partial
HRR function and consequentially platinum resistance, cells harboring BRCA1 E11mut cells also appear to display an intermediate partially PARP inhibitor-resistance phenotype. ${ }^{72}$ Similarly, loss of BRCA1 RING domain function appears insufficient to fully sensitize cells to PARP inhibition, while still predisposing to cancer development. ${ }^{74,75}$

Given the financial implications of targeted therapy use in routine clinical practice, identifying patients most likely to benefit from these drugs is of great importance. Comparison of PARP inhibitor sensitivity in patients harboring $B R C A 1$ exon 11 and RING domain mutations with $B R C A$ wild-type patients is warranted to determine whether these patients represent a truly HRR-deficient population that benefit from PARP inhibition.

\section{$B R C A$ mutations in acquired therapy resistance}

In recent years, secondary $B R C A$ mutations have been implicated in platinum and PARP inhibitor resistance. ${ }^{131}$ These mutations restore $B R C A$ function and HRR proficiency by restoring open-reading frames, reverting mutant alleles back to wild type or removing premature stop codons. ${ }^{132-138}$ Such mutations are a known mechanism of cisplatin and PARP inhibitor resistance when deriving drug-resistant clones in vitro. ${ }^{133-135}$ In keeping with the notion that these secondary events are associated with acquired therapy resistance, secondary BRCA2 mutations have been detected in cell lines derived from patients subsequent to chemotherapy, and these cells are reported to display platinum resistance. ${ }^{133,134,139,140}$

Mutational analysis of clinical specimens has also revealed the presence of secondary $B R C A$ sequence events. ${ }^{132-138}$ Secondary mutations have been detected in both $B R C A 1$ and $B R C A 2$ and correlated with resistance to platinum-based chemotherapy. ${ }^{132-135,138}$ Analysis of $\mathrm{BC}$ and $\mathrm{OC}$ with acquired PARP inhibitor resistance has also uncovered secondary $B R C A$ reversion events and demonstrated their potential to predict platinum and PARP inhibitor resistance at recurrence in $B R C A$-associated OC. ${ }^{136,137}$

\section{Clinical outcome Progression-free survival}

Multiple studies have investigated the prognostic significance of $B R C A$ mutations on PFS and OS within OC. $8,47,53,66,71,141-146$ It has become clear that, together, $B R C A$-associated disease represents a subgroup of $\mathrm{OC}$ that experiences superior PFS, with studies reporting $B R C A$-mutant patients experience PFS around twice that of their $B R C A$ wild-type counterparts. ${ }^{71,144-146}$ Although many studies have failed to 
analyze PFS in a gene-specific manner, others have suggested that $B R C A 1$-associated OC may experience inferior PFS versus $B R C A 2$-associated OC. ${ }^{53,71,147}$ Indeed, some investigators have suggested that $B R C A 1$-associated OC may not experience a PFS benefit compared to $B R C A$ wildtype OC..$^{53,148}$

A recent meta-analysis of over 18,000 OC patients reported superior PFS in both $B R C A 1$ - and $B R C A 2$-associated OCs. ${ }^{149}$ They reported HRs for PFS in BRCA1- and BRCA2associated versus $B R C A$ wild-type OC of $0.68(95 \% \mathrm{CI}$, $0.52-0.89)$ and 0.48 (95\% CI, 0.30-0.75), respectively. Interestingly, a recent study of $B R C A 1$ exon 11 mutationassociated OC revealed no PFS benefit versus the wild-type population, suggesting an interaction between mutation site and PFS. ${ }^{73}$

\section{Overall survival}

A fundamental characteristic of the BRCAness phenotype is superior OS. ${ }^{8,47,53,141,146,150-154}$ Recent work has begun to elucidate the distinction between $B R C A 1$ and $B R C A 2$ mutations with regard to survival..$^{53,66,143,155}$ The current consensus is that both $B R C A 1$ - and BRCA2-mutated OCs experience superior shortterm OS; however, this survival advantage seems exaggerated in BRCA2-versus BRCA1-mutant disease. ${ }^{66,143,147,155,156}$ Fiveyear survival in $B R C A 1$ - and $B R C A 2$-mutant OC is estimated at $\sim 44 \%$ and $52 \%-61 \%$, respectively, versus $\sim 25 \%-42 \%$ in $B R C A$ wild-type OC. ${ }^{53,66,143}$

While $B R C A 2$ carriers continue to experience superior long-term OS, the survival of BRCA1-mutant OC patients appears limited to $\sim 5$ years, with investigators reporting no 10 -year OS advantage in this group. ${ }^{143,155}$ Hyman et al ${ }^{155}$ reported long-term survival benefit in $B R C A 2$-associated serous $O C$ versus the $B R C A$ wild-type population, with no such benefit in the $B R C A 1$-mutant population. Later, Candido-dos-Reis et al ${ }^{143}$ reported 10 -year OS in BRCA1associated, $B R C A 2$-associated and $B R C A$ wild-type OC of $25 \%, 35 \%$ and $30 \%$, respectively, in a large cohort of OC. Their study showed an increasingly detrimental effect for $B R C A 1$ mutation after $\sim 5$ years compared to both $B R C A 2-$ mutated and $B R C A$ wild-type populations.

The recent meta-analysis by $\mathrm{Xu}$ et $\mathrm{al}^{149}$ reported HRs for OS in BRCA1- and BRCA2-associated versus BRCA wild-type OC of 0.73 (95\% CI, 0.63-0.86) and 0.57 (95\% CI, 0.45-0.73), respectively. The study by Dimitrova et $\mathrm{al}^{73}$ of BRCA1 exon 11-associated OC revealed no 5-year OS benefit in this population versus the wild-type population, suggesting that all $B R C A 1$ mutations are not equal in conveying survival advantage.

\section{Key future research avenues Dissecting BRCAIness from BRCA2ness}

A key aim of future research is to continue to dissect the distinct phenotypes of BRCA1- and BRCA2-associated OCs, both from one another and from $B R C A$ wild-type OC. Critically, this will rely on investigators conducting genespecific analyses. It is becoming clear that patients with BRCA2-associated OC experience an exaggerated BRCAness phenotype, displaying superior long-term OS in comparison to $B R C A 1$-associated $\mathrm{OC}$, and emerging data suggest that superior PFS and platinum sensitivity may also be exaggerated in this patient group..$^{53,66,71,143,147,148,155,156}$

Future studies should aim to elucidate the differential sensitivity, if any, of BRCA1- and BRCA2-associated OCs to nonplatinum agents, including nonplatinum DNA-damaging agents, taxanes and PARP inhibitors. It has been suggested that BRCA1-associated OC may be more resistant to paclitaxel, and we await data from independent cohorts investigating the potential impact of $B R C A 1$ and $B R C A 2$ mutations with regard to taxane monotherapy sensitivity. ${ }^{71,82,84-89,91,92}$ While in vitro data suggest that $B R C A 2$-mutant cells are more sensitive to PARP inhibition compared to BRCA1mutant cells, this comparison is yet to be made in the clinical setting. ${ }^{122-130}$ Similarly, characterization of how BRCA1 and $B R C A 2$ mutations may modulate clinical outcome in the context of NAC and IP chemotherapy administration is now warranted. An appreciation of the distinction between BRCA1ness and BRCA2ness by both researchers and clinicians will be paramount in the translation of findings from these studies into clinical practice.

\section{Correlating mutation site and type to chemosensitivity and clinical outcome}

While some studies have investigated the impact of $B R C A 1$ and $B R C A 2$ mutation site on chemosensitivity and $O C$ versus $\mathrm{BC}$ predisposition, the differential impact of distinct $B R C A$ mutation sites remains largely understudied. ${ }^{40-46}$

Growing data suggest that BRCA1 E11mut cells display a distinct partially platinum- and PARP inhibitor-resistant phenotype, and OC patients harboring $B R C A 1$ mutations in exon 11 may not experience a BRCAness survival benefit. ${ }^{72,73}$ Similarly, BRCA1 mutations affecting RING domain function may also not display hypersensitivity to platinum or PARP inhibition. ${ }^{74,75}$ Further investigation of these findings in well clinically annotated OC datasets is now warranted to elucidate whether these groups of patients represent a non-BRCAness, partially HRR proficient subgroup of OC. It may transpire that after removal of these patient groups, 
the characteristics of the remaining "true" BRCA1-mutant HRR-deficient population may be more BRCA2 like.

While some progress has been made investigating site-specific implications of BRCA1 mutation, correlation of $B R C A 2$ mutation site with platinum sensitivity, PARP inhibitor efficacy and survival is yet to be drawn. These investigations are likely to be hindered by the relative rarity of $B R C A 2$ versus $B R C A 1$ mutation and will require large multinational retrospective cohorts of OC. Furthermore, while BRCA1 is multifunctional - providing a rationale for differential modulation of HRR activity with varying mutation site - BRCA2 appears to function almost exclusively in HRR, and phenotypic differences between mutation sites may therefore be subtle. Indeed, BRCA2 mutation site may not influence chemosensitivity or survival.

\section{Characterizing secondary BRCA mutations and their implications for treatment failure}

Increasingly, research efforts have turned to characterizing mechanisms of acquired chemoresistance in $B R C A$-associated OC. Emergence of disease displaying secondary $B R C A$ sequence changes that restore protein function has now been demonstrated in both the preclinical and clinical settings and has been correlated with therapy resistance. ${ }^{132-138}$ Whether these changes arise de novo or through selection of preexisting subclones already present at diagnosis remains an area of keen interest and could influence the selection of NAC versus PDS. Furthermore, investigation into whether different mutation types display differential propensity for reversion - and indeed whether these correlate with prolonged sensitivity to platinum and PARP inhibitors - is yet to be undertaken. Collection of temporally and spatially separated biopsies throughout the disease journey in $B R C A$-associated OC will be invaluable in correlating acquisition of reversion events with clinical outcome, particularly with regard to platinum and PARP inhibitor sensitivity. Studies should aim to identify the frequency at which clinically relevant secondary $B R C A$ mutations arise, the potential therapeutic options to rescue resistance in BRCA-reverted patients and whether these mutations arise de novo or are present in subclonal populations at diagnosis.

\section{Conclusion}

Clearly, substantial advances in defining the characteristics of $B R C A$-associated OC have been made in the past decade. Emerging data are beginning to illuminate the distinction between $B R C A 1$ - and BRCA2-associated OCs, highlighting distinctions between BRCA1ness and BRCA2ness, consistent with the discrete functions of the BRCA1 and BRCA2 gene products. However, dissecting the characteristics of these two distinct OC patient populations from one another is an area of ongoing research.

Perhaps most intriguingly, it is becoming clear that not all BRCA1 mutations are equal and that mutations at particular sites - most notably within exon 11 and those affecting BRCA1 RING domain function - may not confer a BRCAness phenotype. Instead, their role may be confined to compromising the tumor suppressive function of BRCA1, rather than inducing HRR deficiency, and thus chemosensitivity. We await further clinical data on the implications of mutations at these sites, particularly with regard to sensitivity to platinum-based agents and the efficacy of PARP inhibitors. Investigation of the impact, if any, of other $B R C A 1$ mutation sites and of different $B R C A 2$ mutations is eagerly anticipated.

\section{Acknowledgment}

We would like to extend our thanks to the Nicola Murray Foundation for their generous support of the Nicola Murray Centre for Ovarian Cancer Research.

\section{Disclosure}

RLH and MC report no conflicts of interest in this work. CG discloses the following conflicts of interest: AstraZeneca (advisory board attendance, lecture fees and research funding); Clovis (advisory board attendance); Tesaro (advisory board attendance), Novartis (research funding), Nucana (advisory board attendance and research funding) and Aprea (research funding).

\section{References}

1. Siegel RL, Miller KD, Jemal A. Cancer statistics, 2016. CA Cancer J Clin. 2016;66(1):7-30.

2. Prat J. New insights into ovarian cancer pathology. Ann Oncol. 2012;23(Supp1 10):x111-x117.

3. Hollis RL, Gourley C. Genetic and molecular changes in ovarian cancer. Cancer Biol Med. 2016;13(2):236-247.

4. Ledermann JA, Raja FA, Fotopoulou C, Gonzalez-Martin A, Colombo N, Sessa C. Newly diagnosed and relapsed epithelial ovarian carcinoma: ESMO Clinical Practice Guidelines for diagnosis, treatment and follow-up. Ann Oncol. 2013;24(Suppl 6):vi24-vi32.

5. Symeonides S, Gourley C. Ovarian cancer molecular stratification and tumor heterogeneity: a necessity and a challenge. Front Oncol. 2015; $5: 229$.

6. Walsh T, Casadei S, Lee MK, et al. Mutations in 12 genes for inherited ovarian, fallopian tube, and peritoneal carcinoma identified by massively parallel sequencing. Proc Natl Acad Sci U S A. 2011;108(44): 18032-18037.

7. Prat J, Ribe A, Gallardo A. Hereditary ovarian cancer. Hum Pathol. 2005; 36(8):861-870. 
8. Tan DS, Rothermundt C, Thomas K, et al. "BRCAness" syndrome in ovarian cancer: a case-control study describing the clinical features and outcome of patients with epithelial ovarian cancer associated with BRCA1 and BRCA2 mutations. J Clin Oncol. 2008;26(34): $5530-5536$.

9. Liu G, Yang D, Sun Y, et al. Differing clinical impact of BRCA1 and BRCA2 mutations in serous ovarian cancer. Pharmacogenomics. 2012; 13(13):1523-1535.

10. Miki Y, Swensen J, Shattuck-Eidens D, et al. A strong candidate for the breast and ovarian cancer susceptibility gene BRCA1. Science. 1994; 266(5182):66-71.

11. Clark SL, Rodriguez AM, Snyder RR, Hankins GD, Boehning D. Structure-function of the tumor suppressor BRCA1. Comput Struct Biotechnol J. 2012;1(1):e201204005.

12. Hashizume R, Fukuda M, Maeda I, et al. The RING heterodimer BRCA1-BARD1 is a ubiquitin ligase inactivated by a breast cancerderived mutation. J Biol Chem. 2001;276(18):14537-14540.

13. Manke IA, Lowery DM, Nguyen A, Yaffe MB. BRCT repeats as phosphopeptide-binding modules involved in protein targeting. Science. 2003;302(5645):636-639.

14. Yu X, Chini CC, He M, Mer G, Chen J. The BRCT domain is a phosphoprotein binding domain. Science. 2003;302(5645):639-642.

15. Meza JE, Brzovic PS, King MC, Klevit RE. Mapping the functional domains of BRCA1. Interaction of the ring finger domains of BRCA1 and BARD1. J Biol Chem. 1999;274(9):5659-5665.

16. Williams RS, Green R, Glover JN. Crystal structure of the BRCT repeat region from the breast cancer-associated protein BRCA1. Nat Struct Biol. 2001;8(10):838-842.

17. Thakur S, Zhang HB, Peng Y, et al. Localization of BRCA1 and a splice variant identifies the nuclear localization signal. Mol Cell Biol. 1997;17(1):444-452.

18. Deng CX, Brodie SG. Roles of BRCA1 and its interacting proteins. Bioessays. 2000;22(8):728-737.

19. Cortez D, Wang Y, Qin J, Elledge SJ. Requirement of ATM-dependent phosphorylation of brcal in the DNA damage response to double-strand breaks. Science. 1999;286(5442):1162-1166.

20. Abbott DW, Thompson ME, Robinson-Benion C, Tomlinson G, Jensen RA, Holt JT. BRCA1 expression restores radiation resistance in BRCA1-defective cancer cells through enhancement of transcriptioncoupled DNA repair. J Biol Chem. 1999;274(26):18808-18812.

21. Moynahan ME, Cui TY, Jasin M. Homology-directed DNA repair, mitomycin-c resistance, and chromosome stability is restored with correction of a Brca1 mutation. Cancer Res. 2001;61(12):4842-4850.

22. Moynahan ME, Chiu JW, Koller BH, Jasin M. Brcal controls homology-directed DNA repair. Mol Cell. 1999;4(4):511-518.

23. Fabbro M, Savage K, Hobson K, et al. BRCA1-BARD1 complexes are required for p53Ser-15 phosphorylation and a G1/S arrest following ionizing radiation-induced DNA damage. J Biol Chem. 2004; 279(30):31251-31258.

24. Xu B, Kim S, Kastan MB. Involvement of Brca1 in S-phase and G(2)phase checkpoints after ionizing irradiation. Mol Cell Biol.2001;21(10): 3445-3450.

25. Wang B, Matsuoka S, Ballif BA, et al. Abraxas and RAP80 form a BRCA1 protein complex required for the DNA damage response. Science. 2007;316(5828):1194-1198.

26. Roy R, Chun J, Powell SN. BRCA1 and BRCA2: different roles in a common pathway of genome protection. Nat Rev Cancer. 2012;12(1): 68-78.

27. Shahid T, Soroka J, Kong EH, et al. Structure and mechanism of action of the BRCA2 breast cancer tumor suppressor. Nat Struct Mol Biol. 2014;21(11):962-968.

28. Moynahan ME, Pierce AJ, Jasin M. BRCA2 is required for homologydirected repair of chromosomal breaks. Mol Cell. 2001;7(2):263-272.

29. Wong AK, Pero R, Ormonde PA, Tavtigian SV, Bartel PL. RAD51 interacts with the evolutionarily conserved BRC motifs in the human breast cancer susceptibility gene brca2. J Biol Chem. 1997;272(51): 31941-31944.
30. Chen PL, Chen CF, Chen Y, Xiao J, Sharp ZD, Lee WH. The BRC repeats in BRCA2 are critical for RAD51 binding and resistance to methyl methanesulfonate treatment. Proc Natl Acad Sci U S A. 1998;95(9): 5287-5292.

31. Bork $\mathrm{P}$, Blomberg N, Nilges M. Internal repeats in the BRCA2 protein sequence. Nat Genet. 1996;13(1):22-23.

32. Bignell G, Micklem G, Stratton MR, Ashworth A, Wooster R. The $\mathrm{BRC}$ repeats are conserved in mammalian BRCA2 proteins. Hum $\mathrm{Mol}$ Genet. 1997;6(1):53-58.

33. Davies AA, Masson JY, McIlwraith MJ, et al. Role of BRCA2 in control of the RAD51 recombination and DNA repair protein. Mol Cell. 2001;7(2):273-282.

34. Esashi F, Galkin VE, Yu X, Egelman EH, West SC. Stabilization of RAD51 nucleoprotein filaments by the C-terminal region of BRCA2. Nat Struct Mol Biol. 2007;14(6):468-474.

35. Yang H, Jeffrey PD, Miller J, et al. BRCA2 function in DNA binding and recombination from a BRCA2-DSS1-ssDNA structure. Science. 2002;297(5588):1837-1848.

36. Yoshida K, Miki Y. Role of BRCA1 and BRCA2 as regulators of DNA repair, transcription, and cell cycle in response to DNA damage. Cancer Sci. 2004;95(11):866-871.

37. Yuan SS, Lee SY, Chen G, Song M, Tomlinson GE, Lee EY. BRCA2 is required for ionizing radiation-induced assembly of Rad51 complex in vivo. Cancer Res. 1999;59(15):3547-3551.

38. Abbott DW, Freeman ML, Holt JT. Double-strand break repair deficiency and radiation sensitivity in BRCA2 mutant cancer cells. $J$ Natl Cancer Inst. 1998;90(13):978-985.

39. Foray N, Randrianarison V, Marot D, Perricaudet M, Lenoir G, Feunteun J. Gamma-rays-induced death of human cells carrying mutations of BRCA1 or BRCA2. Oncogene. 1999;18(51):7334-7342.

40. King MC, Marks JH, Mandell JB; New York Breast Cancer Study Group. Breast and ovarian cancer risks due to inherited mutations in BRCA1 and BRCA2. Science. 2003;302(5645):643-646.

41. Chen S, Parmigiani G. Meta-analysis of BRCA1 and BRCA2 penetrance. J Clin Oncol. 2007;25(11):1329-1333.

42. Pennington KP, Swisher EM. Hereditary ovarian cancer: beyond the usual suspects. Gynecol Oncol. 2012;124(2):347-353.

43. Gayther SA, Warren W, Mazoyer S, et al. Germline mutations of the BRCA1 gene in breast and ovarian cancer families provide evidence for a genotype-phenotype correlation. Nat Genet. 1995;11(4):428-433.

44. Thompson D, Easton D; Breast Cancer Linkage Consortium. Variation in BRCA1 cancer risks by mutation position. Cancer Epidemiol Biomarkers Prev. 2002;11(4):329-336.

45. Gayther SA, Mangion J, Russell P, et al. Variation of risks of breast and ovarian cancer associated with different germline mutations of the BRCA2 gene. Nat Genet. 1997;15(1):103-105.

46. Rebbeck TR, Mitra N, Wan F, et al. Association of type and location of BRCA1 and BRCA2 mutations with risk of breast and ovarian cancer. JAMA. 2015;313(13):1347-1361.

47. Boyd J, Sonoda Y, Federici MG, et al. Clinicopathologic features of BRCA-linked and sporadic ovarian cancer. JAMA. 2000;283(17): 2260-2265.

48. Garber JE, Offit K. Hereditary cancer predisposition syndromes. J Clin Oncol. 2005;23(2):276-292.

49. Alsop K, Fereday S, Meldrum C, et al. BRCA mutation frequency and patterns of treatment response in BRCA mutation-positive women with ovarian cancer: a report from the Australian Ovarian Cancer Study Group. J Clin Oncol. 2012;30(21):2654-2663.

50. Ramus SJ, Gayther SA. The contribution of BRCA1 and BRCA2 to ovarian cancer. Mol Oncol. 2009;3(2):138-150.

51. The Breast Cancer Linkage Consortium. Cancer risks in BRCA2 mutation carriers. J Natl Cancer Inst. 1999;91(15):1310-1316.

52. Takahashi H, Chiu HC, Bandera CA, et al. Mutations of the BRCA2 gene in ovarian carcinomas. Cancer Res. 1996;56(12):2738-2741.

53. Yang D, Khan S, Sun Y, et al. Association of BRCA1 and BRCA2 mutations with survival, chemotherapy sensitivity, and gene mutator phenotype in patients with ovarian cancer. JAMA. 2011;306(14):1557-1565. 
54. Risch HA, McLaughlin JR, Cole DE, et al. Prevalence and penetrance of germline BRCA1 and BRCA2 mutations in a population series of 649 women with ovarian cancer. Am J Hum Genet. 2001;68(3):700-710.

55. Prat J. Ovarian carcinomas: five distinct diseases with different origins, genetic alterations, and clinicopathological features. Virchows Arch. 2012;460(3):237-249.

56. Gilks CB, Prat J. Ovarian carcinoma pathology and genetics: recent advances. Hum Pathol. 2009;40(9):1213-1223.

57. Kindelberger DW, Lee Y, Miron A, et al. Intraepithelial carcinoma of the fimbria and pelvic serous carcinoma: evidence for a causal relationship. Am J Surg Pathol. 2007;31(2):161-169.

58. Lee Y, Miron A, Drapkin R, et al. A candidate precursor to serous carcinoma that originates in the distal fallopian tube. J Pathol. 2007; 211(1):26-35.

59. Kurman RJ, Shih Ie M. The origin and pathogenesis of epithelial ovarian cancer: a proposed unifying theory. Am J Surg Pathol. 2010;34(3): 433-443.

60. Piek JM, van Diest PJ, Zweemer RP, et al. Dysplastic changes in prophylactically removed Fallopian tubes of women predisposed to developing ovarian cancer. J Pathol. 2001;195(4):451-456.

61. Somigliana E, Vigano P, Parazzini F, Stoppelli S, Giambattista E, Vercellini P. Association between endometriosis and cancer: a comprehensive review and a critical analysis of clinical and epidemiological evidence. Gynecol Oncol. 2006;101(2):331-341.

62. Marquez RT, Baggerly KA, Patterson AP, et al. Patterns of gene expression in different histotypes of epithelial ovarian cancer correlate with those in normal fallopian tube, endometrium, and colon. Clin Cancer Res. 2005;11(17):6116-6126.

63. Cancer Genome Atlas Research Network. Integrated genomic analyses of ovarian carcinoma. Nature. 2011;474(7353):609-615.

64. Tothill RW, Tinker AV, George J, et al. Novel molecular subtypes of serous and endometrioid ovarian cancer linked to clinical outcome. Clin Cancer Res. 2008;14(16):5198-5208.

65. Zorn KK, Bonome T, Gangi L, et al. Gene expression profiles of serous, endometrioid, and clear cell subtypes of ovarian and endometrial cancer. Clin Cancer Res. 2005;11(18):6422-6430.

66. Bolton KL, Chenevix-Trench G, Goh C, et al. Association between BRCA1 and BRCA2 mutations and survival in women with invasive epithelial ovarian cancer. JAMA. 2012;307(4):382-390.

67. Kanchi KL, Johnson $\mathrm{KJ}, \mathrm{Lu} \mathrm{C}$, et al. Integrated analysis of germline and somatic variants in ovarian cancer. Nat Commun. 2014;5:3156.

68. Cormio G, Rossi C, Cazzolla A, et al. Distant metastases in ovarian carcinoma. Int J Gynecol Cancer. 2003;13(2):125-129.

69. Gourley C, Michie CO, Roxburgh P, et al. Increased incidence of visceral metastases in Scottish patients with BRCA1/2-defective ovarian cancer: an extension of the ovarian BRCAness phenotype. J Clin Oncol. 2010;28(15):2505-2511

70. Sekine M, Yoshihara K, Komata D, Haino K, Nishino K, Tanaka K. Increased incidence of brain metastases in BRCA1-related ovarian cancers. J Obstet Gynaecol Res. 2013;39(1):292-296.

71. Vencken PM, Kriege M, Hoogwerf D, et al. Chemosensitivity and outcome of BRCA1- and BRCA2-associated ovarian cancer patients after first-line chemotherapy compared with sporadic ovarian cancer patients. Ann Oncol. 2011;22(6):1346-1352.

72. Wang Y, Bernhardy AJ, Cruz C, et al. The BRCA1-Delta11q alternative splice isoform bypasses germline mutations and promotes therapeutic resistance to PARP inhibition and cisplatin. Cancer Res. 2016;76(9):2778-2790.

73. Dimitrova D, Ruscito I, Olek S, et al. Germline mutations of BRCA1 gene exon 11 are not associated with platinum response neither with survival advantage in patients with primary ovarian cancer: understanding the clinical importance of one of the biggest human exons. A study of the Tumor Bank Ovarian Cancer (TOC) Consortium. Tumour Biol. 2016;37(9):12329-12337.

74. Drost R, Bouwman P, Rottenberg S, et al. BRCA1 RING function is essential for tumor suppression but dispensable for therapy resistance. Cancer Cell. 2011;20(6):797-809.
75. Drost R, Dhillon KK, van der Gulden H, et al. BRCA1185delAG tumors may acquire therapy resistance through expression of RING-less BRCA1. J Clin Invest. 2016;126(8):2903-2918.

76. Struewing JP, Abeliovich D, Peretz T, et al. The carrier frequency of the BRCA1 185delAG mutation is approximately 1 percent in Ashkenazi Jewish individuals. Nat Genet. 1995;11(2):198-200.

77. Roa BB, Boyd AA, Volcik K, Richards CS. Ashkenazi Jewish population frequencies for common mutations in BRCA1 and BRCA2. Nat Genet. 1996;14(2):185-187.

78. Tinker AV, Gebski V, Fitzharris B, et al. Phase II trial of weekly docetaxel for patients with relapsed ovarian cancer who have previously received paclitaxel - ANZGOG 02-01. Gynecol Oncol. 2007;104(3): $647-653$.

79. Katsumata N, Tsunematsu R, Tanaka K, et al. A phase II trial of docetaxel in platinum pre-treated patients with advanced epithelial ovarian cancer: a Japanese cooperative study. Ann Oncol. 2000;11(12): $1531-1536$.

80. Gynecologic Oncology Group; Markman M, Blessing J, et al. Phase II trial of weekly paclitaxel $\left(80 \mathrm{mg} / \mathrm{m}^{2}\right)$ in platinum and paclitaxel-resistant ovarian and primary peritoneal cancers: a Gynecologic Oncology Group study. Gynecol Oncol. 2006;101(3):436-440.

81. Weaver BA. How taxol/paclitaxel kills cancer cells. Mol Biol Cell. 2014;25(18):2677-2681.

82. Quinn JE, Kennedy RD, Mullan PB, et al. BRCA1 functions as a differential modulator of chemotherapy-induced apoptosis. Cancer Res. 2003;63(19):6221-6228.

83. Stordal B, Davey R. A systematic review of genes involved in the inverse resistance relationship between cisplatin and paclitaxel chemotherapy: role of BRCA1. Curr Cancer Drug Targets. 2009;9(3): 354-365.

84. Saiki Y, Ogawa T, Shiga K, Sunamura M, Kobayashi T, Horii A. A human head and neck squamous cell carcinoma cell line with acquired cis-diamminedichloroplatinum-resistance shows remarkable upregulation of BRCA1 and hypersensitivity to taxane. Int J Otolaryngol. 2011;2011:521852.

85. Gilmore PM, McCabe N, Quinn JE, et al. BRCA1 interacts with and is required for paclitaxel-induced activation of mitogen-activated protein kinase kinase kinase 3. Cancer Res. 2004;64(12):4148-4154.

86. Tassone P, Tagliaferri P, Perricelli A, et al. BRCA1 expression modulates chemosensitivity of BRCA1-defective HCC1937 human breast cancer cells. Br J Cancer. 2003;88(8):1285-1291.

87. Chabalier C, Lamare C, Racca C, Privat M, Valette A, Larminat F. BRCA1 downregulation leads to premature inactivation of spindle checkpoint and confers paclitaxel resistance. Cell Cycle. 2006;5(9): 1001-1007.

88. Sung M, Giannakakou P. BRCA1 regulates microtubule dynamics and taxane-induced apoptotic cell signaling. Oncogene. 2014;33(11): $1418-1428$.

89. Fedier A, Steiner RA, Schwarz VA, Lenherr L, Haller U, Fink D. The effect of loss of Brcal on the sensitivity to anticancer agents in p53deficient cells. Int J Oncol. 2003;22(5):1169-1173.

90. Zhou C, Smith JL, Liu J. Role of BRCA1 in cellular resistance to paclitaxel and ionizing radiation in an ovarian cancer cell line carrying a defective BRCA1. Oncogene. 2003;22(16):2396-2404.

91. Kurebayashi J, Yamamoto Y, Kurosumi M, et al. Loss of BRCA1 expression may predict shorter time-to-progression in metastatic breast cancer patients treated with taxanes. Anticancer Res. 2006;26(1b): 695-701.

92. Quinn JE, James CR, Stewart GE, et al. BRCA1 mRNA expression levels predict for overall survival in ovarian cancer after chemotherapy. Clin Cancer Res. 2007;13(24):7413-7420.

93. Tan DS, Yap TA, Hutka M, et al. Implications of BRCA1 and BRCA2 mutations for the efficacy of paclitaxel monotherapy in advanced ovarian cancer. Eur J Cancer. 2013;49(6):1246-1253.

94. Pisano C, Cecere SC, Di Napoli M, et al. Clinical trials with pegylated liposomal doxorubicin in the treatment of ovarian cancer. $J$ Drug Deliv. 2013;2013:898146. 
95. Shaw HM, Hall M. Emerging treatment options for recurrent ovarian cancer: the potential role of olaparib. Onco Targets Ther. 2013;6: 1197-1206.

96. Adams SF, Marsh EB, Elmasri W, et al. A high response rate to liposomal doxorubicin is seen among women with BRCA mutations treated for recurrent epithelial ovarian cancer. Gynecol Oncol. 2011;123(3): 486-491.

97. Safra T, Borgato L, Nicoletto MO, et al. BRCA mutation status and determinant of outcome in women with recurrent epithelial ovarian cancer treated with pegylated liposomal doxorubicin. Mol Cancer Ther. 2011; 10(10):2000-2007.

98. Fujiwara K, Armstrong D, Morgan M, Markman M. Principles and practice of intraperitoneal chemotherapy for ovarian cancer. Int $J$ Gynecol Cancer. 2007;17(1):1-20.

99. Howell SB. Pharmacologic principles of intraperitoneal chemotherapy for the treatment of ovarian cancer. Int J Gynecol Cancer. 2008;18(suppl 1): 20-25.

100. Yan TD, Cao CQ, Munkholm-Larsen S. A pharmacological review on intraperitoneal chemotherapy for peritoneal malignancy. World $J$ Gastrointest Oncol. 2010;2(2):109-116.

101. Dedrick RL, Myers CE, Bungay PM, DeVita VT Jr. Pharmacokinetic rationale for peritoneal drug administration in the treatment of ovarian cancer. Cancer Treat Rep. 1978;62(1):1-11.

102. Alberts DS, Liu PY, Hannigan EV, et al. Intraperitoneal cisplatin plus intravenous cyclophosphamide versus intravenous cisplatin plus intravenous cyclophosphamide for stage III ovarian cancer. $N$ Engl J Med. 1996;335(26):1950-1955.

103. Armstrong DK, Bundy B, Wenzel L, et al. Intraperitoneal cisplatin and paclitaxel in ovarian cancer. N Engl J Med. 2006;354(1):34-43.

104. Markman M, Bundy BN, Alberts DS, et al. Phase III trial of standarddose intravenous cisplatin plus paclitaxel versus moderately high-dose carboplatin followed by intravenous paclitaxel and intraperitoneal cisplatin in small-volume stage III ovarian carcinoma: an intergroup study of the Gynecologic Oncology Group, Southwestern Oncology Group, and Eastern Cooperative Oncology Group. J Clin Oncol. 2001; 19(4):1001-1007.

105. Polyzos A, Tsavaris N, Kosmas C, et al. A comparative study of intraperitoneal carboplatin versus intravenous carboplatin with intravenous cyclophosphamide in both arms as initial chemotherapy for stage III ovarian cancer. Oncology. 1999;56(4):291-296.

106. Yen MS, Juang CM, Lai CR, Chao GC, Ng HT, Yuan CC. Intraperitoneal cisplatin-based chemotherapy vs. intravenous cisplatin-based chemotherapy for stage III optimally cytoreduced epithelial ovarian cancer. Int J Gynaecol Obstet. 2001;72(1):55-60.

107. Wright AA, Cronin A, Milne DE, et al. Use and effectiveness of intraperitoneal chemotherapy for treatment of ovarian cancer. J Clin Oncol. 2015;33(26):2841-2847.

108. Gourley C, Walker JL, Mackay HJ. Update on intraperitoneal chemotherapy for the treatment of epithelial ovarian cancer. Am Soc Clin Oncol Educ Book. 2016;35:143-151.

109. Lesnock JL, Darcy KM, Tian C, et al. BRCA1 expression and improved survival in ovarian cancer patients treated with intraperitoneal cisplatin and paclitaxel: a Gynecologic Oncology Group Study. Br J Cancer. 2013;108(6):1231-1237.

110. Kehoe S, Hook J, Nankivell M, et al. Primary chemotherapy versus primary surgery for newly diagnosed advanced ovarian cancer (CHORUS): an open-label, randomised, controlled, non-inferiority trial. Lancet. 2015;386(9990):249-257.

111. Sato S, Itamochi H. Neoadjuvant chemotherapy in advanced ovarian cancer: latest results and place in therapy. Ther Adv Med Oncol. 2014; 6(6):293-304.

112. Vergote I, Trope CG, Amant F, et al. Neoadjuvant chemotherapy or primary surgery in stage IIIC or IV ovarian cancer. NEngl J Med. 2010; 363(10):943-953.

113. Meyer LA, Cronin AM, Sun CC, et al. Use and effectiveness of neoadjuvant chemotherapy for treatment of ovarian cancer. J Clin Oncol. Epub 2016 Sep 6.
114. Gorodnova TV, Sokolenko AP, Ivantsov AO, et al. High response rates to neoadjuvant platinum-based therapy in ovarian cancer patients carrying germ-line BRCA mutation. Cancer Lett. 2015;369(2):363-367.

115. Schwarz RF, Ng CK, Cooke SL, et al. Spatial and temporal heterogeneity in high-grade serous ovarian cancer: a phylogenetic analysis. PLoS Med. 2015;12(2):e1001789.

116. Blagden SP. Harnessing pandemonium: the clinical implications of tumor heterogeneity in ovarian cancer. Front Oncol. 2015;5:149.

117. Kyle S, Thomas HD, Mitchell J, Curtin NJ. Exploiting the Achilles heel of cancer: the therapeutic potential of poly(ADP-ribose) polymerase inhibitors in BRCA2-defective cancer. Br J Radiol. 2008; 81(Spec No 1):S6-S11.

118. McCabe N, Turner NC, Lord CJ, et al. Deficiency in the repair of DNA damage by homologous recombination and sensitivity to poly(ADPribose) polymerase inhibition. Cancer Res. 2006;66(16):8109-8115.

119. Murai J, Huang SY, Das BB, et al. Trapping of PARP1 and PARP2 by clinical PARP inhibitors. Cancer Res. 2012;72(21):5588-5599.

120. Strom CE, Johansson F, Uhlen M, Szigyarto CA, Erixon K, Helleday T. Poly (ADP-ribose) polymerase (PARP) is not involved in base excision repair but PARP inhibition traps a single-strand intermediate. Nucleic Acids Res. 2011;39(8):3166-3175.

121. Farmer H, McCabe N, Lord CJ, et al. Targeting the DNA repair defect in BRCA mutant cells as a therapeutic strategy. Nature. 2005; 434(7035):917-921.

122. Fong PC, Boss DS, Yap TA, et al. Inhibition of poly(ADP-ribose) polymerase in tumors from BRCA mutation carriers. $N$ Engl J Med. 2009;361(2):123-134.

123. Fong PC, Yap TA, Boss DS, et al. Poly(ADP)-ribose polymerase inhibition: frequent durable responses in BRCA carrier ovarian cancer correlating with platinum-free interval. J Clin Oncol. 2010;28(15):2512-2519.

124. Kaufman B, Shapira-Frommer R, Schmutzler RK, et al. Olaparib monotherapy in patients with advanced cancer and a germline BRCA1/2 mutation. J Clin Oncol. 2015;33(3):244-250.

125. Ledermann J, Harter P, Gourley C, et al. Olaparib maintenance therapy in platinum-sensitive relapsed ovarian cancer. $N$ Engl J Med. 2012;366(15):1382-1392.

126. Swisher EM, Lin KK, Oza AM, et al. Rucaparib in relapsed, platinumsensitive high-grade ovarian carcinoma (ARIEL2 Part 1): an international, multicentre, open-label, phase 2 trial. Lancet Oncol. 2017; 18(1):75-87.

127. Mirza MR, Monk BJ, Herrstedt J, et al. Niraparib Maintenance Therapy in Platinum-Sensitive, Recurrent Ovarian Cancer. $N$ Engl J Med. 2016;375(22):2154-2164.

128. Ledermann J, Harter P, Gourley C, et al. Olaparib maintenance therapy in patients with platinum-sensitive relapsed serous ovarian cancer: a preplanned retrospective analysis of outcomes by BRCA status in a randomised phase 2 trial. Lancet Oncol. 2014;15(8):852-861.

129. Coleman RL, Sill MW, Bell-McGuinn K, et al. A phase II evaluation of the potent, highly selective PARP inhibitor veliparib in the treatment of persistent or recurrent epithelial ovarian, fallopian tube, or primary peritoneal cancer in patients who carry a germline BRCA1 or BRCA2 mutation - an NRG Oncology/Gynecologic Oncology Group study. Gynecol Oncol. 2015;137(3):386-391.

130. Ledermann JA, Harter P, Gourley C, et al. Overall survival in patients with platinum-sensitive recurrent serous ovarian cancer receiving olaparib maintenance monotherapy: an updated analysis from a randomised, placebo-controlled, double-blind, phase 2 trial. Lancet Oncol. 2016.

131. Dhillon KK, Swisher EM, Taniguchi T. Secondary mutations of BRCA1/2 and drug resistance. Cancer Sci. 2011;102(4):663-669.

132. Swisher EM, Sakai W, Karlan BY, Wurz K, Urban N, Taniguchi T. Secondary BRCA1 mutations in BRCA1-mutated ovarian carcinomas with platinum resistance. Cancer Res. 2008;68(8):2581-2586.

133. Sakai W, Swisher EM, Karlan BY, et al. Secondary mutations as a mechanism of cisplatin resistance in BRCA2-mutated cancers. Nature. 2008;451(7182):1116-1120. 
134. Sakai W, Swisher EM, Jacquemont C, et al. Functional restoration of BRCA2 protein by secondary BRCA2 mutations in BRCA2-mutated ovarian carcinoma. Cancer Res. 2009;69(16):6381-6386.

135. Edwards SL, Brough R, Lord CJ, et al. Resistance to therapy caused by intragenic deletion in BRCA2. Nature. 2008;451(7182):1111-1115.

136. Barber LJ, Sandhu S, Chen L, et al. Secondary mutations in BRCA2 associated with clinical resistance to a PARP inhibitor. J Pathol. 2013; 229(3):422-429.

137. Norquist B, Wurz KA, Pennil CC, et al. Secondary somatic mutations restoring BRCA $1 / 2$ predict chemotherapy resistance in hereditary ovarian carcinomas. J Clin Oncol. 2011;29(22):3008-3015.

138. Patch AM, Christie EL, Etemadmoghadam D, et al. Whole-genome characterization of chemoresistant ovarian cancer. Nature. 2015; 521(7553):489-494.

139. Langdon SP, Lawrie SS, Hay FG, et al. Characterization and properties of nine human ovarian adenocarcinoma cell lines. Cancer Res. 1988; 48(21):6166-6172.

140. Stordal B, Timms K, Farrelly A, et al. BRCA1/2 mutation analysis in 41 ovarian cell lines reveals only one functionally deleterious BRCA1 mutation. Mol Oncol. 2013;7(3):567-579.

141. Ben David Y, Chetrit A, Hirsh-Yechezkel G, et al. Effect of BRCA mutations on the length of survival in epithelial ovarian tumors. $J$ Clin Oncol. 2002;20(2):463-466

142. Rubin SC, Benjamin I, Behbakht K, et al. Clinical and pathological features of ovarian cancer in women with germ-line mutations of BRCA1. N Engl J Med. 1996;335(19):1413-1416.

143. Candido-dos-Reis FJ, Song H, Goode EL, et al. Germline mutation in BRCA1 or BRCA2 and ten-year survival for women diagnosed with epithelial ovarian cancer. Clin Cancer Res. 2015;21(3):652-657.

144. Biglia N, Sgandurra P, Bounous VE, et al. Ovarian cancer in BRCA1 and BRCA2 gene mutation carriers: analysis of prognostic factors and survival. Ecancermedicalscience. 2016;10:639.

145. Harter P, Johnson T, Berton-Rigaud D, et al. BRCA1/2 mutations associated with progression-free survival in ovarian cancer patients in the AGO-OVAR 16 study. Gynecol Oncol. 2016;140(3):443-449.

146. Zhong Q, Peng HL, Zhao X, Zhang L, Hwang WT. Effects of BRCA1and BRCA2-related mutations on ovarian and breast cancer survival: a meta-analysis. Clin Cancer Res. 2015;21(1):211-220.
147. Vencken PM, Reitsma W, Kriege M, et al. Outcome of BRCA1compared with BRCA2-associated ovarian cancer: a nationwide study in the Netherlands. Ann Oncol. 2013;24(8):2036-2042.

148. Synowiec A, Wcislo G, Bodnar L, et al. Clinical features and outcomes of germline mutation BRCA1-linked versus sporadic ovarian cancer patients. Hered Cancer Clin Pract. 2016;14:1

149. Xu K, Yang S, Zhao Y. Prognostic significance of BRCA mutations in ovarian cancer: an updated systematic review with meta-analysis Oncotarget. 2017;8(1):285-302.

150. Strickland KC, Howitt BE, Shukla SA, et al. Association and prognostic significance of BRCA1/2-mutation status with neoantigen load, number of tumor-infiltrating lymphocytes and expression of PD-1/PD-L1 in high grade serous ovarian cancer. Oncotarget. 2016; 7(12):13587-13598.

151. McLaughlin JR, Rosen B, Moody J, et al. Long-term ovarian cancer survival associated with mutation in BRCA1 or BRCA2. J Natl Cancer Inst. 2013;105(2):141-148.

152. Chetrit A, Hirsh-Yechezkel G, Ben-David Y, Lubin F, Friedman E, Sadetzki S. Effect of BRCA1/2 mutations on long-term survival of patients with invasive ovarian cancer: the national Israeli study of ovarian cancer. J Clin Oncol. 2008;26(1):20-25.

153. Sun C, Li N, Ding D, et al. The role of BRCA status on the prognosis of patients with epithelial ovarian cancer: a systematic review of the literature with a meta-analysis. PLoS One. 2014;9(5):e95285.

154. Lacour RA, Westin SN, Meyer LA, et al. Improved survival in nonAshkenazi Jewish ovarian cancer patients with BRCA1 and BRCA2 gene mutations. Gynecol Oncol. 2011;121(2):358-363.

155. Hyman DM, Zhou Q, Iasonos A, et al. Improved survival for BRCA2-associated serous ovarian cancer compared with both BRCAnegative and BRCA1-associated serous ovarian cancer. Cancer. 2012; 118(15):3703-3709.

156. Pal T, Permuth-Wey J, Kapoor R, Cantor A, Sutphen R. Improved survival in BRCA2 carriers with ovarian cancer. Fam Cancer. 2007;6(1): 113-119.
OncoTargets and Therapy

\section{Publish your work in this journal}

OncoTargets and Therapy is an international, peer-reviewed, open access journal focusing on the pathological basis of all cancers, potential targets for therapy and treatment protocols employed to improve the management of cancer patients. The journal also focuses on the impact of management programs and new therapeutic agents and protocols on

\section{Dovepress}

patient perspectives such as quality of life, adherence and satisfaction. The manuscript management system is completely online and includes a very quick and fair peer-review system, which is all easy to use. Visit http://www.dovepress.com/testimonials.php to read real quotes from published authors. 